\title{
Association of the genetic variants of luteinizing hormone, luteinizing hormone receptor and polycystic ovary syndrome
}

\author{
Nana Liu ${ }^{1,2,3}$, Yanmin Ma ${ }^{1,4}$, Shuyu Wang ${ }^{4}$, Xiaowei Zhang ${ }^{1,2,3}$, Qiufang Zhang ${ }^{1,2,3}$, Xue Zhang ${ }^{1,2,3}$,
} Li Fu ${ }^{1,2,3}$ and Jie Qiao ${ }^{1,2,3^{*}}$

\begin{abstract}
Background: High circulating luteinizing hormone $(\mathrm{LH})$ level is a typical biochemical feature of polycystic ovary syndrome (PCOS) whose pathophysiology is still unclear. Certain mutations of LH and LH receptor (LHR) may lead to changes in bioactivity of these hormones. The aim of this study was determine the role of the LH and LHR polymorphisms in the pathogenesis of PCOS using a genetic approach.

Methods: 315 PCOS women and 212 controls were screened for the gene variants of LH G1052A and LHR rs61996318 polymorphisms by polymerase chain reaction- restriction fragment length polymorphism (PCR-RFLP).

Results: PCOS patients had significantly more A allele frequency of LH G1052A mutations than controls ( $p=0.001)$. Within PCOS group, carriers of $L H 1052 \mathrm{~A}$ allele had lower $L H(p=0.05)$ and higher fasting glucose levels $(p=0.04)$. No subjects were identified with LHR rs61996318 polymorphisms. A new LHR single nucleotide polymorphism (SNP) was found without clear association with PCOS.
\end{abstract}

Conclusions: Results suggested LH G1052A mutation might influence PCOS susceptibility and phenotypes.

Keywords: Luteinizing hormone, Luteinizing hormone receptor, Polycystic ovary syndrome, Gene polymorphism

\section{Background}

PCOS is one of the most common endocrine disorders in women of reproductive age, and it affects about 1 in 15 women worldwide [1]. The syndrome is characterized by chronic anovulation or infrequent ovulation, hyperandrogenism and numerous follicular cysts in enlarge ovaries. Patients with PCOS are susceptible to infertility, obesity and insulin resistance [1]. Despite extensive research, the precise etiology and mechanisms of PCOS remain largely unknown. Considerable interest in the genetics of PCOS has increased in recent years following increasing number of familial aggregation studies. These studies have demonstrated genetic component of PCOS by the increasing risk ratio of siblings of PCOS individuals compared with that of the general population $[2,3]$.

\footnotetext{
* Correspondence: jie.qiao@263.net

${ }^{1}$ Center for Reproductive Medicine, Department of Obstetrics and Gynecology, Peking University Third Hospital, Beijing 100191, People's Republic of China

Full list of author information is available at the end of the article
}

One typical biochemical feature of PCOS is the high circulating LH level which is thought to be associated with the abnormal patterns of gonadotropin pulsatility in pituitary [4]. LH is a member of the glycoprotein hormone family that also includes follicle stimulating hormone (FSH), thyroid-stimulating hormone and human chorionic gonadotropin. These hormones are $\alpha$ : $\beta$ heterodimers in which the $\alpha$-subunit is common to all hormones and the $\beta$-subunit is unique and confers biologic specificity $[5,6]$. The effect of LH is mediated by LHR which is expressed in the theca cells and granulose cells. Abnormal LH signaling is believed to play a permissive role in augmenting ovarian androgen production in PCOS and increasing the likelihood of anovulation $[1,7]$.

Studies have shown that $L H \beta$ and $L H R$ gene mutations may change the structure or function of the LH and LHR, either activating or inactivating their bioactivity, which cause anovulation, amenorrhea and polycystic ovary in women [8-10]. There are compelling evidences 
for the genetic determinism of $L H \beta$ and $L H R$ for PCOS, although the results of different populations and loci of mutation showed inconsistencies. Two missense point mutations in the $L H \beta$ gene (Trp 8 Arg and Ile $15 \mathrm{Thr}$ ) were reported to associate with PCOS in Japan and obese PCOS women in UK. But a study of obese PCOS from north European found $L H \beta$ gene $(\operatorname{Trp} 8$ Arg and Ile $15 \mathrm{Thr}$ ) were in lower frequency [11-13]. Another $L H \beta$ gene variant G1502A in exon 3 (Gly102Ser) was found to be higher in Singapore Chinese women who had menstrual disorders [14]. Yet a Korean research found no difference of $L H \beta$ gene Gly102Ser in PCOS patients [15]. Women with LHR mutations often show amenorrhea and infertility [5]. Chen et al. had conducted genome-wide association study (GWAS) of PCOS in Han Chinese women and found strong evidence of associations between PCOS and LHR gene loci [16]. PCOS had lower frequency of $L H R$ 18insLQ genotype compared with controls ( $24.9 \%$ vs $28 \%$ ) in a study which there was about $15 \%$ lower risk for PCOS per minor allele copy, though the lower LHR 18insLQ frequency was not significant after Bonferroni's correction between PCOS and controls [17]. Given the above evidences, we decide to study both $L H \beta$ and $L H R$ gene variants in PCOS patients of Chinese Han women, intending to further elucidate the genetic mutation mechanism of $L H$ and $L H R$ with PCOS.

\section{Methods}

\section{Patients}

315 Chinese Han women with PCOS and 212 controls were recruited at Peking University Third Hospital Reproductive Centre from January 2010 to March 2012. This study was approved by the institutional ethics committee of the Hospital, and written informed consent was obtained from each subject.

PCOS was diagnosed according to the 2003 Rotterdam criteria [18]. Two out of three of the following criteria were met for the diagnosis: oligo-ovulation and/or anovulation,irregular menstrual cycle ( less than eight periods per year, or cycles that are longer than 35 days, and amenorrhoea is absence of menstruation for more than 3 months without pregnancy), clinical and/or biochemical signs of hyperandrogenism (Ferriman-Gallwey score $\geq 6$ or total serum testosterone $>2.8 \mathrm{nmo} / \mathrm{l}$ ) and polycystic ovaries (PCO) by transvaginal ultrasound $(\geq 12$ or more follicles in each ovary measuring $2-9 \mathrm{~mm}$ in diameter, and/or increased ovarian volume, $>10 \mathrm{ml}$ ). Patients with the following disorders were excluded: hyperprolactinemia, nonclassic congenital adrenal hyperplasia, Cushing's syndrome, androgen secreting neoplasm and thyroid dysfunction. The control group included age matched women with regular menstrual cycles. They were infertile women for tubal obstruction and/or male factor.
They had no clinical or biochemical signs of hyperandrogenism and no polycystic ovaries. All subjects (range from 20 to 40 years old) had not taken hormonal therapy (including oral contraceptives) for at least 3 months prior to testing.

\section{Hormonal and biochemical measures}

We collected fasting blood samples of all subjects during the follicular phase of a menstrual cycle (spontaneous or bleeding after progestin withdrawal). Serum LH, FSH, testosterone $(\mathrm{T})$, androstenedione (A) and insulin concentrations were determined by chemiluminescence immunoassay. Glucose levels, total cholesterol (CHO) and triglycerides (TG) were determined by oxidase methods. High-density lipoprotein (HDL) by synthetic polymer/detergent HDL-C assay and low-density lipoprotein (LDL) by surfactant LDL-C assay. Body mass index (BMI) was calculated as body weight (kg) divided by body height squared $\left(\mathrm{m}^{2}\right)$. Waist hip ratio (WHR) was calculated as hipline divided by waistline.

\section{Genotyping}

Genomic DNA was extracted from peripheral blood leukocytes using the standard salting out method [19]. The purity and concentration of the isolated DNA was measured. Primers of $L H \beta$ G1502A forward: AGTCTGAGACCTGTGGGGTCAGCTT, reverse: GGAGGATCCGGGTGTCAGGGCTCCA. Primers of LHR rs61996318: forward: TGATGGTGGTGGTGATGATG, reverse: GGTTTCTAGCCA GCCAGTTG. PCR amplification was performed as Nam Keun Kim et al. described [15]. The fragment of LHR rs61996318 amplification is 379 bp. PCR products were analyzed by RFLP using Enzyme Rsal and then they were given to electrophoresis on a $2 \%$ agarose gel stained with ethidium bromide. In Genebank, LHR rs61996318 mutation is from $\mathrm{G} \rightarrow \mathrm{A}$, and the LHR protein of corresponding position changes from Gln to Lys.

\section{DNA sequencing}

The LHR PCR products (315 PCOS and 122 controls) were sequenced in both directions using primers matching intronic boundaries (primer sequences as mentioned before). All were done by automatic genotype sequencing instrument (ABI3730XL,BigdyeV3.1) in Peking Huada Gene Company.

\section{Statistical analysis}

Normal distribution of all clinical parameters was analyzed using the Kolmogorov-Smirnov test. Comparisons of normal distribution continuous variables between groups were independent student's $t$ test. When continuous variables were not normal distribution, Mann-Whitney U-test was used. Fisher's exact test and chi-square test 
was used for analyzing the associations between categorical variables. All analyses were performed by SPSS software version 18.0 (SPSS Inc. Chicago, IL, USA). NC-pass was used to perform power calculation. Tests of statistical significance were two sided and taken as significant when $\mathrm{p} \leq 0.05$.

\section{Results}

\section{Clinical parameters}

The basal demographical, hormonal and biochemical parameters of controls and PCOS women are summarized in Table 1. The age and WHR between two groups were similar. Similar with most studies, LH and testosterone levels were higher in PCOS patients compared with that of controls, the same as BMI, LH/FSH ratio, A and TG levels. FSH level was significantly lower in PCOS. There were no significant difference in the levels of fasting glucose, fasting insulin, HDL, LDL and $\mathrm{CHO}$ between PCOS patients and controls (Table 1).

\section{Variants of $L H \beta$ and $L H R$ genes polymorphisms}

In PCOS group, there are $3 L H \beta$ A1052A homozygous patients, $10 \mathrm{LH} \beta$ G1052A heterozygous patients, and the gene variants frequencies were $1.0 \%$ and $3.2 \%$ respectively. There was no one $L H \beta$ G1052A gene variant in 212 controls. The $L H \beta$ G1052A heterozygous frequency in PCOS was significantly higher than that in controls $(p=0.007)$ and A allele frequency with PCOS patients was more than that in controls ( $\mathrm{p}=0.001$, Table 2).

There were all wild type of LHR rs61996318 SNP polymorphisms in PCOS and control subjects. In order to
Table 2 LH $\beta$ G1052A genotype distribution in PCOS and control women

\begin{tabular}{llll}
\hline LH $\boldsymbol{\beta}$ genotype & $\mathbf{P C O S}(\mathbf{N}=\mathbf{3 1 5})$ & Controls(N = 212) & $\mathbf{P}$ \\
\hline G1052G & $302(95.8 \%)$ & $212(100 \%)$ & - \\
G1052A & $10(3.2 \%)$ & $0(0 \%)$ & 0.007 \\
A1052A & $3(1.0 \%)$ & $0(0 \%)$ & 0.27 \\
Alleles & - & - & - \\
G & $614(97.5 \%)$ & $414(100 \%)$ & - \\
A & $16(2.5 \%)$ & $0(0 \%)$ & 0.001 \\
\hline
\end{tabular}

check its accuracy, the PCR products of 315 PCOS and 122 controls were subjected to genetic DNA sequencing and confirmed the same result with PCR-RFLP.

\section{A new SNP in $L H R$ gene}

In the $L H R$ PCR products DNA sequencing map, we found a new SNP in $L H R$ gene NT27762960 position near exon 7 , where there was a loss of base $A$, in which the gene sequencing changes from TAGCC A GAG to TAGCC_GAG.

In PCOS group, there were 2 homozygous of this new SNP and in controls there were $5(\mathrm{p}=0.02)$. But the heterozygous frequency with PCOS was higher than that in controls $(21.3 \%$ vs. $13.9 \%, \mathrm{p}=0.11)$. There was no significant difference of missing base frequency in the two groups (11.3\% vs. $11.1 \%$, Table 3$)$.

\section{PCOS phenotype by different $L H \beta$ and $L H R$ genotypes}

Within the PCOS cohort, genotypes of the $L H \beta$ G1052A mutations were not associated with general clinical signs,

Table 1 Clinical and endocrine-metabolic parameters in PCOS and control women

\begin{tabular}{lll}
\hline Parameters & PCOS(N=315) & Controls(N=212) \\
\hline Age $(\mathrm{yr})$ & $32.48 \pm 3.88$ & $33.02 \pm 4.26$ \\
BMI(kg/m2) & $24.18 \pm 3.91$ & $22.43 \pm 3.57^{*}$ \\
WHR & $0.83 \pm 0.07$ & $0.83 \pm 0.06$ \\
Oligo- or anovulation (\%) & 91.42 & $0^{*}$ \\
PCO $(\%)$ & 93 & $0^{*}$ \\
Testosterone ( $\mathrm{nmol} / \mathrm{L})$ & $1.80 \pm 1.10$ & $0.91 \pm 0.44^{*}$ \\
A(nmol/L) & $13.66 \pm 5.56$ & $6.35 \pm 2.16^{*}$ \\
LH(m/U/ml) & $9.09 \pm 6.42$ & $4.20 \pm 2.69^{*}$ \\
FSH(m/U/ml) & $6.19 \pm 1.94$ & $7.31 \pm 2.09^{*}$ \\
LH/FSH & $1.50 \pm 0.99$ & $0.61 \pm 0.43^{*}$ \\
Fasting glucose $(\mathrm{mmol} / \mathrm{L})$ & $4.94 \pm 0.70$ & $5.07 \pm 0.88$ \\
Fasting insulin(ulU/ml) & $13.09 \pm 9.29$ & $12.92 \pm 8.63$ \\
CHO(mmol/L) & $4.87 \pm 0.87$ & $4.68 \pm 0.81$ \\
TG $(\mathrm{mmol} / \mathrm{L})$ & $1.55 \pm 1.00$ & $0.93 \pm 0.48^{*}$ \\
HDL(mmol/L) & $1.26 \pm 0.31$ & $1.31 \pm 0.25$ \\
LDL(mmol/L) & $2.99 \pm 1.44$ & $2.76 \pm 0.84$ \\
\hline
\end{tabular}

Independent student's t test and Mann-Whitney U-test; Data are described in mean \pm SD; BMI: body mass index; WHR: waist hip ratio; PCO: polycystic ovary syndrome; A: serum androstenedion; CHO: total cholesterol; TG: triglycerides; HDL: High-density lipoprotein; LDL:low-density lipoprotein. *: P $\leq 0.05$. 
Table 3 LHR new SNP genotype distribution in PCOS and control women

\begin{tabular}{llll}
\hline LHR new SNP genotype & $\mathbf{P C O S}(\mathbf{N}=\mathbf{3 1 5})$ & Controls(N=122) & $\mathbf{P}$ \\
\hline wild type & $246(78.1 \%)$ & $100(82.0 \%)$ & - \\
homozygous type & $2(0.6 \%)$ & $5(4.1 \%)$ & 0.03 \\
heterozygous type & $67(21.3 \%)$ & $17(13.9 \%)$ & 0.11 \\
Alleles & - & - & - \\
A & $559(88.7 \%)$ & $217(88.9 \%)$ & - \\
Missing & $71(11.3 \%)$ & $27(11.1 \%)$ & 0.93 \\
\hline
\end{tabular}

Chi-square test; Data are presented as number and (percentage). $(-)=$ not tested.

such as BMI, waist hip ratio, amenorrhea and $\mathrm{PCO}$ (Table 4). Carriers of the $L H \beta 1052 \mathrm{~A}$ allele showed lower LH level $(p=0.05)$, higher fasting glucose level $(p=0.04)$ and the power calculation was $79 \%$ and $14 \%$ respectively. Although the testosterone and androstenedione levels were similar between two $L H \beta$ genotypes groups, the testosterone levels were $2.35,2.58$ and $4.09 \mathrm{nmol} / \mathrm{L}$ with three $L H \beta$ A1052A homozygous PCOS subjects respectively (data wasn't shown in Table 4). FSH, TG, fasting insulin levels and LH FSH ratio were similar between two groups.

For patients with new SNP of LHR gene in PCOS group, the $\mathrm{LH}$, fasting glucose and testosterone levels didn't differ between mutated type and wild type. No association of the new SNP genotypes with BMI, WHR, amenorrhea or PCO was observed. FSH, LH/FSH, TG and fasting insulin levels were also similar between two groups (Table 4).

As mentioned above, symptoms or signs of PCOS include irregular menses (IM), clinical or biochemical hyperandrogenism (HA) and PCO according to 2003 Rotterdam criteria. There are four possible diagnostic subcategories of PCOS i.e. IM/HA/PCO, IM/HA, HA/ $\mathrm{PCO}$, and IM/PCO. We analyzed and compared the distribution of $L H \beta$ G1052A genotype and $L H R$ new SNP genotype according to these four subgroups of our subject pool (Figure 1). The $L H \beta$ G1052A gene variants frequency was $9.1 \%$ in IM/HA subgroup and $7.4 \%$ in $\mathrm{HA} / \mathrm{PCO}$ subgroup. Both are slightly higher than that of IM/HA/PCO subgroup and IM/PCO subgroups (3.1\% and $3.8 \%)$. But the difference of $\mathrm{A}$ allele frequency was not significant among four subgroups $(p=0.46)$. The four PCOS subgroups showed similar gene variants frequency of the LHR new SNP. IM/HA/PCO subgroup was $23 \%$; IM/HA subgroup was $13.60 \%$; HA/PCO was $18.5 \%$ and IM/PCO was $22.9 \%(\mathrm{p}=0.74)$.

\section{Discussion}

Until now, the relationship between LH signaling pathway and PCOS has not been defined clearly. Besides the twocell-two-gonadotrophin theory, LH plays a critical role in the folliculogenesis. During the second half of the follicular phase, LH regulates mRNA concentrations in granulose cells for numerous genes that function in autocrine and paracrine signaling which can help the follicle developing well $[20,21]$. LH promotes the secretion of androgens by ovarian theca cells, which may result in follicular maturation arrest [22]. LHR is over expressed in theca cells and granulose cell from PCOS patients [23,24]. Discovery of SNP as new markers of the human genome opened novel ways to demonstrate genetic associations of candidate genes to complex disorders. A number of functional SNPs have been described in $L H$ and $L H R$ genes which may affect the LH and LHR bioactivity $[11,25]$. In the current study, we investigated both the genotype of $L H \beta$ G1052A and $L H R$ rs61996318 in Han Chinese PCOS patients. $L H \beta$

Table 4 Clinical and endocrine-metabolic parameters with different LHß G1052A genotype and LHR new SNP genotype in PCOS patients

\begin{tabular}{|c|c|c|c|c|}
\hline & $L H \beta 1052 \mathrm{G} / \mathrm{G}(\mathrm{N}=302)$ & $L H \beta 1052 \mathrm{G} / \mathrm{A}+\mathrm{A} / \mathrm{A}(\mathrm{N}=13)$ & LHR wild type $(\mathrm{N}=246)$ & LHR mutated type $(\mathrm{N}=69)$ \\
\hline $\mathrm{BMI}(\mathrm{kg} / \mathrm{m} 2)$ & $24.24 \pm 3.93$ & $22.74 \pm 3.83$ & $24.20 \pm 3.91$ & $24.15 \pm 4.03$ \\
\hline WHR & $0.83 \pm 0.07$ & $0.81 \pm 0.05$ & $0.83 \pm 0.07$ & $0.82 \pm 0.06$ \\
\hline Amenorrhea,n(\%) & 276(91.39) & $11(84.62)$ & 223(90.65) & 65(94.20) \\
\hline PCO,n(\%) & 282(93.37) & $11(84.62)$ & $227(92.28)$ & $66(95.65)$ \\
\hline $\mathrm{LH}(\mathrm{mlU} / \mathrm{ml})$ & $9.23 \pm 6.44$ & $5.71 \pm 4.07^{*}$ & $8.85 \pm 6.47$ & $9.96 \pm 6.06$ \\
\hline $\mathrm{FSH}(\mathrm{mlU} / \mathrm{ml})$ & $6.21 \pm 1.91$ & $5.90 \pm 2.28$ & $6.19 \pm 1.97$ & $6.23 \pm 1.82$ \\
\hline LH/FSH & $1.52 \pm 0.99$ & $1.09 \pm 1.06$ & $1.47 \pm 1.02$ & $1.61 \pm 0.88$ \\
\hline Testosterone ( $\mathrm{nmol} / \mathrm{L}$ ) & $1.80 \pm 1.10$ & $1.91 \pm 1.04$ & $1.79 \pm 1.07$ & $1.86 \pm 1.22$ \\
\hline $\mathrm{A}(\mathrm{nmol} / \mathrm{L})$ & $13.66 \pm 5.59$ & $13.76 \pm 4.59$ & $13.67 \pm 5.50$ & $13.63 \pm 5.78$ \\
\hline Fasting glucose $(\mathrm{mmol} / \mathrm{L})$ & $4.92 \pm 0.63$ & $5.32 \pm 1.54^{*}$ & $4.93 \pm 0.73$ & $4.98 \pm 0.60$ \\
\hline Fasting insulin(ulU/ml) & $9.70 \pm 6.30$ & $13.27 \pm 9.38$ & $12.83 \pm 9.13$ & $14.24 \pm 9.88$ \\
\hline $\mathrm{TG}(\mathrm{mmol} / \mathrm{L})$ & $1.56 \pm 1.01$ & $1.26 \pm 0.49$ & $1.55 \pm 0.97$ & $1.55 \pm 1.07$ \\
\hline
\end{tabular}

Independent student's $t$ test and Mann-Whitney U-test; Data are described in mean $\pm S D$. $P \leq 0.05$ was considered statistically significant. ${ }^{*}$ : $\leq 0.05$. 

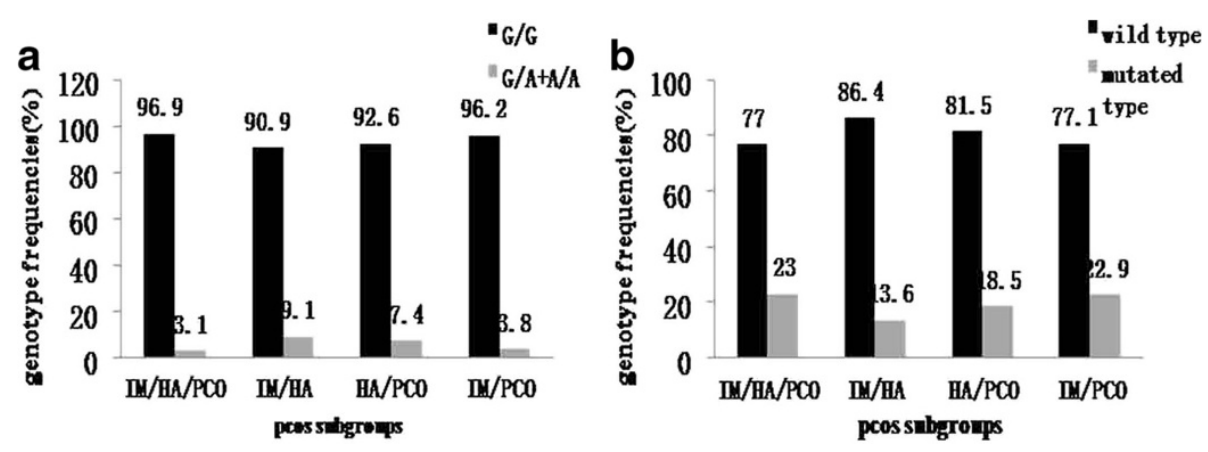

Figure 1 Distribution of $L H \beta$ G1052A genotype (a) and LHR new SNP genotype (b) in four subgroups of PCOS. PCOS patients were divided into four subgroups according to 2003 Rotterdam criteria (IMA/HA/PCO, IM/HA, HA/PCO and IM/PCO). There were no significant differences of these two gene mutations among four subgroups of PCOS (LHB G1052A genotype: $p=0.46$; $L H R$ new SNP genotype: $p=0.74$ ).

1052A allele frequency in PCOS group was higher than that of controls $(\mathrm{p}=0.001)$. Within PCOS group, $L H \beta 1052 \mathrm{~A}$ gene variants showed influence on LH level $(\mathrm{p}=0.05)$ and fasting glucose level $(\mathrm{p}=0.04)$. No $L H R$ rs61996318 mutation was found in our subjects. For the first time, we found a new SNP in LHR gene NT27762960 where a base A was missing. To our knowledge, this is the first study to investigate the correlations of both $L H \beta$ and LHR genotypes in PCOS.

In our study, the frequencies of $L H \beta$ G1052A homozygous and heterozygous variants were $1.0 \%$ (3/315) and $3.2 \%(10 / 315)$ respectively in PCOS. In contrast, there was no $L H \beta$ G1052A mutation (0/212) in control group. The frequency of A allele in PCOS was significantly higher than controls $(p=0.001)$. Similar with our result that the $L H \beta$ G1052A frequency was about $4.2 \%$, Ramanujam et al. also reported a $L H \beta$ G1052A variant frequency of $4 \%(7 / 176)$ in Singapore Chinese women with menstrual disorders and no one A allele in the control subjects $(0 /$ 200). They speculated $L H \beta$ G1052A mutations affected gonadal function, and the micro heterogeneity was related to menstrual irregularity [14]. But Kim et al. studied 108 Korean women patients with endometriosis or PCOS and found none of them were $L H \beta$ G1052A homozygous gene variants [15]. Ramanujam et al. didn't find any variant either in Malays or Indians PCOS women [26]. These results suggested that ethnicity and environment may influence the genetic variability in PCOS patients. Specifically, different ethnical and regional group may express different $L H \beta$ G1052A genotype.

$L H \beta$ G1052A mutation is a single missense mutation in exon 3 of the $L H \beta$ gene which replaces glycine with serine at amino acid 102 [13]. Haavisto et al. had uncovered another LH mutation (Trp8Arg and Ile15Thr, $\mathrm{V}$-LH $\beta$ ) which alters the biological function of LH with an elevation of in vitro bioactivity compared to that of wild type LH. Heterozygous women for the V-LH $\beta$ allele had higher levels of serum testosterone, and estradiol $[12,27]$. Within PCOS group, we found that carriers of the $L H \beta$ 1052A allele had lower LH level (5.71 vs 9.23 $\mathrm{mIU} / \mathrm{ml}, \mathrm{p}=0.05)$. The power calculation to $\mathrm{LH}$ level between two $L H \beta$ G1052A genotypes within PCOS was $79 \%$. Additionally, testosterone levels of three $L H \beta$ A1052A homozygous carriers were 2.35, 2.58 and $4.09 \mathrm{nmol} / \mathrm{L}$ (data were not shown in table) respectively. It has been well known that LH plays an important role in secreting testosterone. This phenomenon strongly suggested $L H \beta$ G1052A gene variants had an effect on LH protein and may enhance the LH bioactivity. Lamminen et al. had found that $L H \beta$ G1052A mutation may not affect receptor binding and bioactivity of $\mathrm{LH}$ [28]. However, PCOS is a heterogeneous endocrine disorder, which is involved in many factors, such as genetics and environment factors. Thus, the biological function of $L H \beta$ 1052A gene variants within PCOS microenvironment needs to be further studied.

Carriers of the $L H \beta 1052 \mathrm{~A}$ allele had higher fasting glucose level (5.32 vs $4.92 \mathrm{mmol} / \mathrm{l}, \mathrm{p}=0.04$ ). Higher fasting glucose usually represents insulin resistance or metabolic dysfunction, which is one of the most common clinical features of PCOS. Studies have confirmed insulin can enhance the responsiveness of theca cell and granulose cell to $\mathrm{LH}$ in PCOS women [24]. Insulin resistance and $\mathrm{LH}$ interacted with each other and increase the severity of PCOS.

We found a new SNP in LHR gene NT27762960 position near exon 7 where base A was missing. The amino acid sequence of $L H R$ encoded by the exons 2-10 has been shown to confer hormone specificity and binding to the gonadotropin [29]. Homozygous or compound heterozygous inactivating gene variants of the $L H R$ cause gonadal resistance to $\mathrm{hCG}$ and $\mathrm{LH}$, and the latter event 
causes feedback to pituitary to result in the rising $\mathrm{LH}$ level. However, the clinical phenotypes associated with these mutations are closely correlated with the severity of the mutation [30]. Piersma et al. found that $L H R$ 18insLQ mutation, Asn291Ser and Ser312Asn render the LHR bioactivity, which resulted LHR was insensitive to LH [25,31]. Valkenburg et al. found in Caucasian PCOS that the LHR 18insLQ frequency was lower in PCOS patients and about $15 \%$ lower risk for PCOS per minor allele copy. However, Asn291Ser and Ser312Asn were not obviously associated with PCOS. In their study the 18insLQ homozygous carriers showed $24.1 \%$ lower levels of estrogen (179 vs $236 \mathrm{pmol} / \mathrm{l}$ ) [17]. In our study, the missing A allele frequency was similar between PCOS and controls (11.3\% vs. $11.1 \%, \mathrm{p}=0.93)$. These LHR new polymorphisms were in Hardy-Weinberg equilibrium (HWE) within the PCOS population and controls. Within PCOS group, LH level of new LHR SNP was a little higher than wild type $(9.96 \mathrm{vs.} 8.85 \mathrm{mIU} / \mathrm{ml})$, but the difference wasn't significant, and the same as levels of testosterone and androstenedione. We also didn't find the relationship between new LHR gene SNP and other PCOS phenotypes like PCO, BMI, fasting glucose, and fasting insulin levels. We didn't find the association between the new SNP of LHR gene with PCOS susceptibility and phenotype. Further study in this aspect is needed.

High LH level is a significant character of PCOS. Although LH level was no longer as a diagnostic factor of PCOS in 2003 Rotterdam criteria, LH level or LH FSH ratio still acts as a diagnostic criterion of PCOS in some Asian countries such as Japan[32]. Therefore, we analyzed these two gene variants frequencies within four subgroups of PCOS. The minor alleles frequencies of $L H \beta$ G1052A genotype and $L H R$ new SNP genotype weren't significantly different among four subgroups. This result showed that these $L H \beta$ G1052A genotype and LHR new SNP genotype had little relationship with PCOS diagnosis.

Based on this study, we had some limitations, such as: 1) the number of homozygous and heterozygous with $L H \beta$ and $L H R$ mutation was small; 2) $L H \beta$ G1052A mutation was not in HWE; 3) The power calculation to fasting glucose level between two LHB G1052A genotypes within PCOS group was low. We thought this phenomenon was related to the low $L H \beta$ G1052A mutation frequency, which was also testified in three other studies $[14,15,26]$.

\section{Conclusions}

In summary, the current study provides new insight into the role of LH genetics in the pathophysiology of PCOS. We found the minor allele frequency of
LH $\beta$ G1052A was higher with PCOS; PCOS carriers of $L H \beta$ 1052A allele had lower $\mathrm{LH}$ level and high fasting glucose level. We speculated $L H \beta$ G1052A mutation may contribute to the pathogenesis of PCOS. The $L H R$ rs61996318 SNP maybe highly conserved in Chinese Han women. We also found a new LHR SNP for the first time in PCOS and further study is in process to elucidate the associations between this new LHR SNP and PCOS.

\section{Competing interests}

All of the authors declare that they have no competing interests.

\section{Acknowledgements}

This work was partly supported by Doctoral Foundation of Education Ministry of China (grant numbers: 20090001110090), 2009-2011 National Natural Science Foundation for Distinguished Young Scholar (grant numbers: 30825038) and the National Natural Science Foundation of China (grant number: 81170538).

\section{Author details}

${ }^{1}$ Center for Reproductive Medicine, Department of Obstetrics and Gynecology, Peking University Third Hospital, Beijing 100191, People's Republic of China. ${ }^{2}$ Key Laboratory of Assisted Reproduction, Ministry of Education, Beijing 100191, China. 'Beijing Key Laboratory of Reproductive Endocrinology and Assisted Reproduction, Beijing 100191, China.

${ }^{4}$ Reproductive Medical Centre, Beijing Obstetrics and Gynecology Hospital affiliated of Capital Medical University, Beijing 100026, China.

\section{Authors' contributions}

$\mathrm{NL}$ and YM participated in the design of the study, carried out the experiment, performed the statistical analysis and drafted the manuscript. SW, XZ and QZ were involved in revision of manuscript drafts. LF and XZ participated in collection of blood samples. JQ contributed to the design of the experiment and was responsible for finalizing manuscript. All authors read and approved the final manuscript.

Received: 5 January 2012 Accepted: 30 April 2012

Published: 30 April 2012

\section{References}

1. Norman RJ, Dewailly D, Legro RS, Hickey TE: Polycystic ovary syndrome. Lancet 2007, 370:685-697.

2. Azziz R, Kashar-Miller: Family history as a risk factor for the polycystic ovary syndrome. J Pediatr Endocrinol Metab 2000, 13(Suppl. 5):1303-1306.

3. Deligeoroglou E, Kouskouti C, Christopoulos P: The role of genes in the polycystic ovary syndrome: Predisposition and mechanisms. Gynecol Endocrinol 2009, 25:603-609.

4. Rebar R, Judd HL, Yen SS, Rakoff J, Vandenberg G, Naftolin F: Characterization of the inappropriate gonadotropin secretion in polycystic ovary syndrome. J Clin Invest 1976, 57:1320-1329.

5. Themmen AP: An update of the pathophysiology of human gonadotrophin subunit and receptor gene mutations and polymorphisms. Reproduction 2005, 130:263-274.

6. Ascoli M, Fanelli F, Segaloff DL: The Lutropin/Choriogonadotropin Receptor, A 2002 Perspective. Endocr Rev 2002, 23:141-174.

7. Balen $\mathrm{AH}$ : Hypersecretion of luteinizing hormone and the polycystic ovary syndrome. Hum Reprod 1993, 8:123-128.

8. Huhtaniemi I, Alevizaki M: Gonadotrophin resistance. Best Pract Res Clin Endocrinol Metab 2006, 20:561-576.

9. Huhtaniemi IT, Themmen AP: Mutations in Human Gonadotropin and Gonadotropin-Receptor Genes. Endocrine 2005, 26:207-217.

10. Themmen APN, Huhtaniemi IT: Mutations of Gonadotropins and Gonadotropin Receptors: Elucidating the Physiology and Pathophysiology of Pituitary-Gonadal Function. Endocr Rev 2000, 21:551-583.

11. Suganuma N, Furui K, Furuhashi M: Screening of the mutations in luteinizing hormone b-subunit in patients with menstrual disorders. Fertil Steri 1995, 336:673-675. 
12. Rajkhowa M, Talbot JA, Jones PW: Prevalence of an immunological LH beta-subunit variant in a UK population of healthy women and women with polycystic ovary syndrome. Clin Endocrinol (Oxf) 1995, 4:297-303.

13. Tapanainen JS, Koivunen R, Fauser BC, Taylor AE, Clayton RN, Rajkowa M, White D, Franks S, Anttila L, Pettersson KS, Huhtaniemi IT: A New Contributing Factor to Polycystic Ovary Syndrome: The Genetic Variant of Luteinizing Hormone. J Clin Endocrinol Metab 1999, 84:1711-1715.

14. Ramanujam LN, Liao WX, Roy AC, Loganath A, Goh HH, Ng SC: Association of molecular variants of luteinizing hormone with menstrual disorders. Clin Endocrinol (Oxf) 1999, 51:243-246.

15. Kim NK, Nam YS, Ko JJ, Chung HM, Chung KW, Cha KY: The luteinizing hormone b-subunit exon 3(Gly102Ser) gene mutation is rare in Korean women with endometriosis and polycystic ovary syndrome. Fertil Steril 2001, 75:1238-1239.

16. Chen ZJ, Zhao $H$, He L, Shi $Y$, Qin $Y$, Shi $Y$, Li Z, You L, Zhao J, Liu J, Liang $X$, Zhao $X$, Zhao J, Sun $Y$, Zhang B, Jiang $H$, Zhao D, Bian $Y$, Gao X, Geng L, Li Y, Zhu D, Sun X, Xu JE, Hao C, Ren CE, Zhang Y, Chen S, Zhang W, Yang A, Yan J, Li Y, Ma J, Zhao Y: Genome-wide association study identifies susceptibility loci for polycystic ovary syndrome. Nat Genet 2011, 43:55-59.

17. Valkenburg O, Uitterlinden AG, Piersma D, Hofman A, Themmen AP, de Jong FH, Fauser BC, Laven JS: Genetic polymorphisms of GnRH and gonadotrophic hormone receptors affect the phenotype of polycystic ovary syndrome. Hum Reprod 2009, 24:2014-2022.

18. The Rotterdam ESHRE/ASRM-Sponsored PCOS consensus workshop group: Revised 2003 consensus on diagnostic criteria and long-term health risks related to polycystic ovary syndrome (PCOS). Hum Reprod 2004, 19:41-47.

19. Miller SA, Dykes DD, Polesky H: A salting procedure for extracting DNA from nucleated cells. Nucleic Acid Res 1998, 16:1215.

20. Lindeberg M, Carlström K, Ritvos O, Hovatta O: Gonadotrophin stimulation of non-luteinized granulosa cells increases steroid production and the expression of enzymes involved in estrogen and progesterone synthesis. Hum Reprod 2007, 22:401-406.

21. Sasson R, Rimon E, Dantes A, Cohen T, Shinder V, Land-Bracha A, Amsterdam A: Gonadotrophin-induced gene regulation in human granulosa cells obtained from IVF patients. Modulationof steroidogenic genes, cytoskeletal genes and genes coding for apoptotic signaling and protein kinases. Mol Hum Reprod 2004, 10:299-311.

22. Laven JS, Imani B, Eijkemans MJ, Fauser BC: New approach to polycystic ovary syndrome and other forms of anovulatory infertility. Obstet Gynecol Surv 2002, 57:755-767.

23. Jakimiuk AJ, Weitsman SR, Navab A, Magoffin DA: Luteinizing hormone receptor, steroidogenesis acute regulatory protein, and steroidogenic enzyme messenger ribonucleic acids are overexpressed in thecal and granulosa cells from polycystic ovaries. J Clin Endocrinol Metab 2001, 86:1318-1323.

24. Willis DS, Watson H, Mason HD, Galea R, Brincat M, Franks S: Premature Response to Luteinizing Hormone of Granulosa Cells from Anovulatory Women with Polycystic Ovary Syndrome: Relevance to Mechanism of Anovulation. J Clin Endocrinol Metab 1998, 83:3984-3991.

25. Piersma D, Berns EM, Verhoef-Post M, Uitterlinden AG, Braakman I, Pols HA Themmen AP: A common polymorphism renders the luteinizing hormone receptor protein more active by improving signal peptide function and predicts adverse outcome in breast cancer patients. J Clin Endocrinol Metab 2006, 91:1470-1476.

26. Ramanujam L, Liao WX, Roy AC, Ng SC, Ratnam SS: Molecular Variants of Luteinizing Hormone in Three Populations of Southeast Asia. Hum Hered 1998, 48:232-234.

27. Haavisto AM, Pettersson K, Bergendahl M, Virkamäki A, Huhtaniemi I: Occurrence and biological properties of a common genetic variant of luteinizing hormone. J Clin Endocrinol Metab 1995, 80:1257-1263.

28. Lamminen $T$, Jiang M, Manna PR, Pakarinen $P$, Simonsen $H$, Herrera RJ, Huhtaniemi I: Functional study of a recombinant form of human LH betasubunit variant carrying the Gly(102)Ser mutation found in Asian populations. Mol Hum Reprod 2002, 8:887-892.

29. Braun T, Schofield PR, Sprengel R: Amino-terminal leucine-rich repeats in gonadotropin receptors determine hormone selectivity. EMBO J 1991, 10:1885-1890.

30. Segaloff DL: Diseases Associated with Mutations of the Human Lutropin Receptor. Prog Mol Biol Trans/ Sci 2009, 89:97-114.
31. Müller T, Gromoll J, Simoni M: Absence of Exon 10 of the Human Luteinizing Hormone (LH) Receptor Impairs LH, But Not Human Chorionic Gonadotropin Action. J Clin Endocrinol Metab 2003, 88:2242-2249.

32. Ma CS, Lin Y, Zhang CH, Xu H, Li YF, Zhang SC, Tan Y, Quan S, Xing FQ: Preliminary study on the value of ratio of serum luteinizing hormone/follicle-stimulatinghormone in diagnosis of polycystic ovarian syndrome among women with polycystic ovary. Zhonghua Fu Chan Ke Za Zhi 2011, 46:177-180.

doi:10.1186/1477-7827-10-36

Cite this article as: Liu et al.: Association of the genetic variants of luteinizing hormone, luteinizing hormone receptor and polycystic ovary syndrome. Reproductive Biology and Endocrinology 2012 10:36.

\section{Submit your next manuscript to BioMed Central and take full advantage of:}

- Convenient online submission

- Thorough peer review

- No space constraints or color figure charges

- Immediate publication on acceptance

- Inclusion in PubMed, CAS, Scopus and Google Scholar

- Research which is freely available for redistribution 